\title{
Role of Social Worker in National Center for Victims of Domestic Violence
}

\author{
Sabina Belshaku, MSC \\ Lecturer at Department of Social Sciences, \\ Faculty of Education Sciences, \\ "Aleksander Xhuvani" Elbasan University, Albania
}

doi: 10.19044/esj.2016.v12n23p199 URL:http://dx.doi.org/10.19044/esj.2016.v12n23p199

\begin{abstract}
Social worker on shelter should be familiar with the process of domestic violence. This involves the various forms of violence, consequences of violence, and ways of assisting victims of domestic violence. The aim of this study is to determine the overall objective of the role of social workers in national centers for victims of domestic violence. Also, this study aims to contribute to the improvement of services provided by the state for battered women. Through the application of qualitative research method conducted in the center of battered women retained in the estimated service, Kamëz was a source of comfort to abused women and how they are integrated into the society after leaving the shelter. This study relies on the theory of Social Work Feminist intended to be applied to a study type of ethnographic concentrated in the center. This is based on its history, operation, the view of the center, and the data obtained from documents, archives, and available data center. The data was obtained through observation, focus groups, and interviews with mixed application of semi-structured and structured. Most of the respondents claim that they know and have used the shelter services. Hence, we can say that there is a positive assessment of quality. We conclude that existing services are effective enough, enjoyable, and qualitative. Women emphasized that the state should intervene more to meet their needs, such as the need for more information and sensitization about violence. This requires an increase in economic aid from the state as well as important services, such as psycho-social support. Also, the role of social workers in national centers for victims of domestic violence should be expanded and strengthened.
\end{abstract}

Keywords: Social Work, Feminist Theory of Social Work, Violence Against Women, Shelter 


\section{Introduction}

Shelters should be careful of not setting rules, but its aim should be in facilitating the operation of the shelter without regard for the safety of residents. It should focus on meeting the needs of battered women. Feminist Theory of Social Work helps to give a clearer view of the shelter and work with battered women. Access to the theory identifies the function and role of social workers in the center. Feminist Theory of Social Work is part of feminist theory. The authors claim that in the area of large delivery of diversity of feminism and feminist approaches, they are more common principles which are applicable to both individuals and organizational as well. Individual and social changes resulting from the change of views on the roles of women and men are evidence of feminist influence in both private and public structures. Feminist theory has influenced not only an individual or a collective life, but has also influenced the way through which they develop and use knowledge about individuals and society. However, feminism has been transformed into a social thought and social action.

Social workers are influenced by feminist thought and action. Recent literature is, however, calling for a review of social work. This is on the basis of new knowledge about women and new interpretations of existing theories on prior beliefs about the roles of women in the society. Feminism is now used by some social workers as a convenient theoretical framework to study the experiences of women in society. It is also used to develop intervention strategies to change these experiences positively. Social workers should advocate for the validity and usefulness of the services provided for women in the society, their needs, and their assessment from a feminist perspective. The feminist analysis of education, health, and employment policies provides a framework for evaluating relevant social functioning and the design and implementation of interventions. However, this intervention is used to improve, increase, or restore the functionality of individuals, families, groups, organizations, communities, and society. These are the core tasks of social workers in practice. Subsequently, the combination of feminism in the thoughts and actions of social workers is essential for social change; and thus, it is clearly in line with the fundamental purpose of social work and social action in improving social conditions.

Social feminist work was about working with women - gender which is a central social division. In addition, the development of women's welfare was a priority for social workers as they see them as individuals and not as a wife or mother.

In the eighties, feminist social work, in and out, deeply pulled out the issues raised by the sexual abuse of children. Domestic violence also rose steadily as an issue which opines that social workers should be taken seriously. This, however, was not put into consideration until the nineties 
when feminists were able to make clear links between domestic violence and the welfare of the children.

In the mid-nineties, a host of criticism appeared. In an important article, Wise (1995) argued against some of the central assumptions of feminist who wrote about social work. She argued that non-statutory agencies were inappropriate models based on legal practices on social work. In addition, she stated that the power that social workers can exercise was potentially positive.

In general, in the late nineties, there was a continuous attempt to create a "major project" under allied with feminism and anti-racism versions, social work (for example; Dominelli, 1998). However, it was the last gasp and it could not predict the development of a form of overall project feminist whose goal is to develop a theory of the universal. Also, its aim is to practice to cover the range of activities covered by social work and also emphasize the violence of women. Although feminists think it is important to ask why people are violent, it is, thus, based on the assumption that they (feminists) know why. Therefore, there is only one answer to this assumption, and this answer should be communicated to all including men themselves.

\section{Key Concepts of Feminist Social Work}

- The consciousness of Sensitive is a strategy that serves to stimulate knowledge and change.

- Reflexivity as a research tool, and its subsequent adoption as an element of practice.

- Dialoguing, egalitarian relationships, is a practice tool that empowers the values of women.

Consequently, the shape of a person, social identity, and social process varies as a significant aspect of the creation and intervention in diverse relationships.

National Center for Victims of Domestic Violence has started work on 25.04.2011, based on the order of the Prime Minister no. 36 dated 18.03.2011, in order to provide services to help women victims of domestic violence and their children. Thus, the center's mission is to provide services, intervention and treatment programs against domestic violence, protect victims of domestic violence and their children, and at the same time, increasing the accountability of offenders who are perpetrators of domestic violence. It aims to empower beneficiaries to move towards independence and support themselves. Additionally, the center provides social assistance, quality services, consistent with contemporary standards of victims of domestic violence (women, girls, baby boys up to 16 years old) residential assistance accommodation, psycho-emotional, health, legal, safety, and rehabilitation services. Their aim is to promote their training, rehabilitation, 
inclusion, dignity, and their integration into normal life. Informed and aware public opinion, family members, and relatives can help to protect and provide support for the rehabilitation and reintegration process for a better future.

\section{Role of Social Workers in the Shelter}

Is the role of social workers necessary for battered women's shelter? Does social worker support women in shelters to achieve their objectives until the issue of shelters and the integration process? Is social worker a factor for the successful functioning of work at the shelter? Consequently, these are some of the major study questions.

The social worker of the shelter should be familiar with the process of domestic violence, forms of violence, consequences of violence, and the various ways of assisting them. More important is the continuous training of professional social worker. Thus, this training must always be updated with the government strategies regarding the provision of services in the center.

The social worker must differentiate between their private lives from their profession. Thus, this should not include the views, beliefs, attitudes, behaviors, sexual orientation, and personal relationships with the beneficiaries of the center. The social worker of the shelter should be fit and readily available to resolve cases and emergency situations that could endanger the woman's life inside the center. This usually occurs when the abuser, male or its user, locates the address of the shelter. Others include severely affected health cases of the beneficiary in an interpersonal conflict between the beneficiaries or beneficiary acute emotional crisis.

\section{However, shelter social worker case runs in four phases:}

\section{- Study Phase}

In the study phase, the social worker is familiar with the case, and studies on it. At this stage, she collects data to assist her in handling the case. This is after listening to the story - information about the life of the beneficiary, experiences, and life experiences such as feelings, emotions, the initial perceptions and sensitivities. Constructive interaction and relationship is the most important part of this phase. Thus, the social worker should create a climate of security cooperation and ensure that the beneficiary is ready to offer alternative solutions.

\section{- Evaluation Stage}

In this case, management is the most important stage. Here, the social worker identifies the strengths and weaknesses of the beneficiary. This process helps the social worker to schedule a personal intervention program or work plan. 


\section{- Intervention Phase}

It is the phase in which the beneficiary has gained confidence and is ready to make the necessary changes in her life about the situation. Social worker beneficiary decides jointly with the objectives of the process. In the relationship between the beneficiary and the social worker, three main elements are important: authenticity, mutual trust, and clarity of agreements

\section{- Final Stage}

At this stage, the social worker identifies the changes made by the beneficiary. Also, the beneficiary is aware that the state stand-alone. The social worker considers a key moment by the beneficiary assessment instruments during the process. Also, she assesses the changes occurring as a successful woman. Here, we are assessing the situation and the situation of women deployed at the moment of leaving the shelter.

Social workers who work in the shelter must recognize and prevent the phenomenon of burn-out. The term "burn - out" by Freudenberger is used to describe the way in which social services operators are gradually exhausted and how wealthy industrial energy desires to undertake their commitments. Burn-out is a consuming state of physical, emotional, and mental stress caused by a long and steady work (Girdi, Everly \& Dusek, 1996). It is caused by several factors, among which the most important is exposure to trauma experienced by women. Other factors that cause burn-out include heavy workload and unclear roles and responsibilities. In addition, there is a function to reverse the role attributed to the needs of the service. Therefore, this creates a state of confusion within the staff resulting to a constant change in personnel staff, loses energy and risked losing the sense of the group, the lack of a common line, feeling of futility, the uselessness and the conflicts between employees. In personal terms, burn-out is manifested by anxiety, fears not there before, a sense of uncertainty, and difficulty to decide relationship. Often times, during the coffee break or during leisure, shelter workers discuss about their work and the beneficiaries. As such, they take their problems home. Consequently, this brings about the conditions of nervousness due to their frustrated dreams and unresolved problems and insomnia problems. Burn-out is described as a gradual process of disillusionment which occurs in four stages: • Enthusiasm - This is the initial stage where some professionals invest all their energy at work which brings pleasure and all. Some of them are more idealistic than others and often times identify with their beneficiaries. They have a lack of realism in assessing the situations that they have to work. - Stagnation - This stage refers to a blocking process and hopelessness drunken by the desire to achieve change. - Frustration - At this stage, the professional feels weak, with no power to help and act, and no feeling of being useful. Some complain and blame others, upset while addressing their supervisor, and have 
a feeling of guilt and anger. - Apathy -The final stage where there is professional frustration is a very good cognitive emotion perception for beneficiaries, but not to those Ill to work and who do not achieve the expected results.

Given that burn-out is a form of exhaustion and psychological and emotional consumption, emphasis should be placed on the prevention activity which is performed through supervision. Therefore, it should be mandatory for all staff who works with women. Given that shelter workers are exposed to the experiences and stories of women, the supervision process would help in finding new ways of reflecting about the work done by the beneficiaries. In addition, it would help in raising the awareness experiences at the emotional and cognitive level. The main purpose of the supervision is seen in improving labor. Thus, the supervision must be done by a psychologist or a qualified professional in the field of counseling. It is important for them to be a figure outside the group to keep a distance during the supervision process.

\section{Methodology}

The methodology of this study is aimed to achieve the study sample selected by qualitative method. Violence women, children, and the center's staff workers are housed in the center. Data was obtained from focus groups, women, and workers of the center through interviews that was conducted. An interview was conducted with a woman who has come from the center and she is undergoing the process of integration into the society. Semistructured interviews are a form of terrorist application of feminist social work. The sample comprises of 45 interviews in total which include staff of shelter, beneficiaries of the shelter, specialists from the municipality, employees of the ministry, and the police force. From the shelter, we interviewed 5 women. 3 out of these women were living in the center, while 2 are currently in the process of integration. Thus, the center currently houses 9 women. The goal of the interviews is to obtain the perception of beneficiaries in connection with the effectiveness of services and the quality of existing services. Furthermore, interview questions were studied to provide three different types of information in the context of three major research objectives. They are:

\section{Identification and verification of the level of recognition of services.}

\section{Recognition of the judgment on services used.}

\section{Recommendations and suggestions for improvement.}

The research is in the context of achieving its overall objective of contributing to the improvement of the services provided by the state for battered women. The interviews entail answering questions about what services they provide for women when they are in the center and what 
services were offered to them when they are leaving the center. In a way, this became a confrontation as women compared their answers with that of the center's staff.

Through the application of qualitative research method aimed at the search conducted in the center of battered women retained in the estimated service, Kamëz was a source of comfort to abused women and how they are integrated into the society after they left the shelter. This study relies on the theory of Social Work Feminist intended to be applied to a study type of ethnographic concentrated in the center. This is based on its history, data, operation, the view of the center, the data obtained from documents, archives, and available data center. The data was obtained through observation, focus groups, and interviews with mixed application of semistructured and structured.

Feminist Theory of Social Work with its focus on the private/public helps to outline the study on the relationship that exists in the State's social service provided and based on the needs of battered women. This movement appreciates how state social service prepares abused women to be integrated into the society as they leave the center. What do raped women get from the service center? What benefit do they derive at the shelter? When and what are the criteria before they are ready to leave the shelter? What are the needs of battered women as they leave the center to be reintegrated into the society? What is the possibility or probability of these women returning to center stage after the end of reintegration? These are the main questions to be answered through research as a way for assessing the specific needs of battered women.

\section{Result and Conclusion}

Although it has been illustrated in the literature that feminism has not effectively served to assess the needs and realities of women raped, feminist research approaches are important because they contextualize domestic violence and gender inequality, patriarchal structures. In preserving the spirit of the philosophy of empowerment and support, it is important for shelters to review the rules set for life inside the shelter. This would ensure that these rules are not oppressive. Also, it gives participants the opportunity make decisions by themselves.

Subsequently, it is important to have some rules for living in a shelter to guaranty the security of all the participants in the program. Nevertheless, the shelter should not recreate the dynamics of powers that are present in abusive relationships. For example, these dynamics are recreated when the shelter's staff takes the role of "setters rules". Therefore, this makes the participants to have an awareness of their position, that of "followers of the rules". Shelters should be careful not to set rules. Their sole purpose is to 
facilitate the operation of the shelter. This is without regard for the safety of residents. Thus, this is considered as one of the tips to meet the needs of battered women.

Consequently, interviews are used in providing a lot of information which is important for the achievement of our objective.

\section{Role of Social Worker}

The social worker at the shelter is somehow a reference figure. They make rules in the shelter and often show an act of respect. There are times when women create a relationship of dependency with the social worker and this causes them to leave. The social worker should always be a step behind the women who were raped by giving her freedom of choice. Most of the respondents alleged that they feel very weak, helpless, lack self-confidence, do not feel ready to do anything, and felt as though their whole world has collapsed. Their first contact with the social worker was the counseling they received which was their only hope. The role of the social worker is very important because it stimulates women and grants them the opportunity to deal with life challenges. In addition, the center helps in sensitizing the women.

\section{Recognition of Shelter Services}

All women claimed to be aware of the existence of the state shelter services. This is in favor of women who were referred to health services, economic assistance, and vocational training. Most of the respondents claim to have had knowledge of the services and the shelter from different sources such as from friends, from the media, and from public institutions. Most of the information was obtained by reading the leaflets, posters, and other instruments.

\section{The Use of Shelter Services}

Almost all women who were interviewed claimed to have used the existing services. These services include health, economic assistance, psychological counseling, legal counseling, and vocational training. This is consistent with the current conditions of women and they have an immediate need for economic independence. These women have experienced situations of violence and discrimination. Most of the respondents do not want to return to home seeking employment. As a result, they built a new life away from their abuser.

\section{Rating Services}

Most of the respondents claim that they know and have used the shelter services. Thus, they have a positive assessment of the quality of the 
services. We conclude that existing services are effective enough, enjoyable, and qualitative. Women emphasized that the state should intervene more to meet their needs, such as the need for an information and sensitization about violence. This, therefore, requires an increase in economic aid from the state as well more services that requires psycho-social support.

\section{Suggestions for Services}

On the basis of the answers given, the respondents have a positive perception of the quality of services. However, it is necessary for it to be strengthened and improved. In identifying services for women who were referred to vocational training, 4 of the women opines that it would be better to improve the information given about the services.

\section{References:}

Boyd, N. Murch, M. \& Walker, V. (1983). Violence in the Workplace. Convention (EU) "Protection of human rights and fundamental freedoms", adopted in 1950, entered into force in 1953).

Convention "For the Elimination of All Forms of Discrimination Against Women" (CEDAW) Albania accedes to the Convention on the Law No. 7767, dated 09.11.1993 after approval by the Assembly in 1993.

Dobash \& Dobash (1979). Merita (Vaso) Xhumari, Tirana 2009. Process and Social Policy Institutes.

Dominelli Lena (2002). Feminist Social Work Theory and Practice

European Social Card (1965). The low 9669 dated 18.12.2006 "On measures against domestic violence".

Freudenberger, Herbert, \& Richelson Geraldine (1980). Burn Out: The high cost of High Achievement. What it is and how to survive it. Bantam Books

Gordon, D.A., Everly, G.S. \& Dusek, D.E. (1996). Controlling Stress and Tension, Allyn \& Bacon, Needham Heights, MA.

Gelles \& Cornell (1990). Intimate Violence in Families. Newbury Park, CA: Sage Publications.

International 32. Convention "On Civil and Political Rights (ICCPR)

International 34. Convention "On economic, social and cultural rights" (ICESCR).

Melanie Lord, Anthony Greiter \& Zuflo Tursunovic (2005). Feminist Theory PNUD In Albania: http // www.undp.org.al

Slade, A. S. Brooker, K. Fay,

The Universal Declaration of Human Rights (UDHR), adopted and proclaimed by General Assembly Resolution 217A (III) of 10 December 1948.

The Beijing Declaration and Beijing Platform for Action in 1995.

W. Lewchuk, S. Preston, D. Dimitrova. Improving Work 
Walker (1979). Battered Women. New York: Harper and Row. www.jennygilmore.com.au

www.womanabuse.ca/

www.tandfonline.com

www.soc.iastate.edu/sapp/Feminist.ppt

www.ablong www.icadvinc.orman.com/...

www./sw/ppt/rs/swr_approaches.ppt

www.feministstudies.org/rk.utoronto.ca/ 